Revista Eletrônica de Direito Processual - REDP.

Rio de Janeiro. Ano 15. Volume 22. Número 2. Maio a Agosto de 2021

Periódico Quadrimestral da Pós-Graduação Stricto Sensu em Direito Processual da UERJ

Patrono: José Carlos Barbosa Moreira (in mem.). ISSN 1982-7636. pp. 540

www.redp.uerj.br

\title{
A PRIVATIZAÇÃo do PROCESSO EXECUTIVO CIVIL PORTUGUÊS E A MUTAÇÃO DO PARADIGMA CLÁSSICO PARA O NEOLIBERALISMO E SEUS LIMITES JURÍDICOS ${ }^{1}$
}

\author{
THE PRIVATIZATION OF THE PORTUGUESE CIVIL EXECUTIVE PROCESS \\ AND THE MUTATION OF THE CLASSIC PARADIGM FOR NEOLIBERALISM \\ AND ITS LEGAL LIMITS
}

Luís Manuel Pica

\begin{abstract}
Doutorando em Ciências Jurídicas - Públicas na Escola de Direito da Universidade do Minho e Mestre em Direito. Docente no Instituto Politécnico de Beja, Portugal. Investigador no JusGov - Centro de Governação e Justiça da Escola de Direito da Universidade do Minho (Portugal). Email: luispica280@gmail.com
\end{abstract}

RESUMO: A privatização da ação executiva revela-se como um fenómeno que tem marcado a transferência de poderes que cabiam na alçada do domínio público, concretamente do poder jurisdicional do Estado, para o domínio privado, sendo estes chamados a praticar atos inerentes e próprios do tribunal em sede de processo executivo. A privatização assenta numa lógica de auxílio e de cooperação entre o setor privado e o Estado, sendo aproveitado o potencial daqueles na atuação e na prática de atos de natureza jurisdicional com o intuito de obter uma justiça mais célere, eficiente e equitativa num mercado que se pretende ágil, coerente e juridicamente seguro.

PALAVRAS-CHAVE: Privatização; Ação Executiva; Agente de Execução; Eficiência Judicial; Poder Jurisdicional.

ABSTRACT: The privatization of the executive action to be a phenomenon that has marked the transfer of powers that fit within the public domain, specifically the judicial

\footnotetext{
${ }^{1}$ Artigo recebido em 25/03/2021, sob dispensa de revisão.
} 
Revista Eletrônica de Direito Processual - REDP.

Rio de Janeiro. Ano 15. Volume 22. Número 2. Maio a Agosto de 2021

Periódico Quadrimestral da Pós-Graduação Stricto Sensu em Direito Processual da UERJ

Patrono: José Carlos Barbosa Moreira (in mem.). ISSN 1982-7636. pp. 540

www.redp.uerj.br

power of the State, to the private domain, are called to perform inherent and proper acts of the court in an executive court. Privatization in a logic of aid and cooperation between the private sector and the State, being used the potential doses in the performance and practice of acts of a judicial nature with the intuition of obtaining a faster, and fairer justice in a market that is intended to be agile, coherent and safe.

KEYWORDS: Privatization; Executive Action; Execution Agent; Judicial Efficiency; Judicial Court.

\section{INTRODUÇÃO}

O aproveitamento do potencial privado para a realização das atividades que se encontram constitucionalmente investidas no poder jurisdicional dos estados, assinala a emergência de um sistema judicial que procura uma migração para a esfera privada. $O$ resultado da colocação dos sujeitos privados numa posição de participação ativa na ação executiva em que grande parte das tarefas são praticadas por estes, passando de um sistema que não dispensava a intervenção de agentes e funcionários judiciais supervisionados pelo juiz para um outro em que aquela intervenção se apresenta meramente subsidiária, no que respeita ao juiz, e meramente residual ou quase excecional quanto aos oficiais de justiça.

Por considerarmos que a sua operacionalização resulta de um complexo de transformações produzidas na configuração do processo executivo, o presente estudo será dirigido à análise do fenómeno de privatização do processo executivo enunciado, perspetivando-o através do arquétipo jurídico-compreensivo fornecido por aquele processo.

O objetivo assumido será levado a efeito mediante a estruturação do estudo da privatização da ação executiva em três fases: o conceito de privatização da ação executiva e da sua motivação. Nestas duas primeiras partes dirigimos os nossos esforços ao tratamento de conceitos e estruturas compreensivas que constituem pressupostos inultrapassáveis para a compreensão do fenómeno de privatização. O tratamento da privatização da ação executiva é promovida em atenção ao seu conceito, à sua motivação, à sua forma de operacionalização e aos seus limites. 


\section{O CONCEITO de PRIVATIZAÇÃo da AÇÃo EXECUTiVA E A SUA MOTIVAÇÃO}

A primeira abordagem a fazer ao conceito de privatização assenta pela sua consideração enquanto fenómeno dinâmico, geral e como uma realidade movida de uma esfera dominial para outra esfera dominial, o qual constituirá o ponto de partida e de chegada, necessariamente de um domínio público para um domínio privado. Por se assentar enquanto fenómeno geral e, portanto, não exclusivamente jurídico, deve-se compreender que os conceitos de domínio público e privado devem ser considerados num sentido lato, na exata medida em que a realidade a privatizar não será necessariamente jurídica, ou pelo menos exclusivamente.

A polissemia e a heterogeneidade que justifica a adoção de um conceito de privatização que passa por uma delimitação do seu objeto em termos amplos, depende daquelas esferas que se pretende privatizar, nomeadamente quando a privatização assenta em esferas de natureza social, económica, política ou jurídica. Por este motivo, deve ter-se, contudo, assente a ideia de que o fenómeno de privatização numa conceção geral é caraterizada pela transferência de uma certa realidade, de um domínio tido por público para um domínio tido como privado, sendo suscetíveis de recondução naquele conceito de operações que comportem tais caraterísticas.

Quanto à aceção que nos interessa aqui apresentar, não sendo possível a abordagem das demais por questões de economia, deve-se consignar que enquanto fenómeno jurídico, a privatização apresenta-se como um conceito suscetível de recondução num complexo heterogéneo de significados, pelo que a sua polissemia nos obriga, face a heterogeneidade subjacente, que a sua delimitação seja realizada em sentido amplo.

A privatização, de uma forma mais ou menos intuitiva, revela-se como um fenómeno de transmissão de poderes públicos para os privados. Ou seja, o fenómeno privatizador pode consistir na transferência para o domínio privado de tarefas públicas, cuja prossecução constituía, originariamente, encargo do Estado. A designação de privatização de tarefas ou privatização da prossecução do interesse público, assume um papel determinação num fenómeno de reformulação do próprio modelo de Estado vigente. Dir-se-á que a privatização de tarefas representa uma forma de privatização que consiste 
Revista Eletrônica de Direito Processual - REDP.

Rio de Janeiro. Ano 15. Volume 22. Número 2. Maio a Agosto de 2021

Periódico Quadrimestral da Pós-Graduação Stricto Sensu em Direito Processual da UERJ

Patrono: José Carlos Barbosa Moreira (in mem.). ISSN 1982-7636. pp. 540

www.redp.uerj.br

em colocar tarefas públicas ao encargo de privados, contribuindo de forma direta para o fenómeno de privatização da prossecução do interesse público. Como alguma doutrina advoga estaremos perante uma fuga para o Direito Privado, pois verifica-se, em tais, casos, que a privatização operada respeita à própria natureza do direito aplicável pelas entidades públicas e no qual se promove uma substituição das formas jurídicas públicas de atuação e organização por fórmulas jurídicas privadas, de modo a convergir com o exercício de funções públicas em subordinação a um misto de normas de natureza diversificada ${ }^{2}$.

Teleologicamente, e em termos não patológicos, o aproveitamento do potencial privado para exercício e aumento das funções públicas e da necessidade de que ao desenvolvimento das atividades públicas, é incrementado por razões de eficácia e de eficiência que estes podem conseguir na atuação pública. Em termos patológicos, esta forma de privatização tende a ser associada a uma tentativa de libertação de vinculações derivadas do princípio da legalidade a que as submete o ordenamento jurídico, procurando exonerar-se dos limites e limitações que são impostas à sua atuação, conseguindo uma maior liberdade de decisão. Contudo, não poderá aqui resultar uma atuação puramente privatizada no sentido patológico apontado, pois a atuação sob sujeição das normas de direito privado, acaba por não se adotar na sua plenitude, acabando por se levantar verdadeiras limitações e vinculações jurídico-públicas relativamente à atividade privada no seio desta privatização.

Não obstante, perspetivando-se a realidade privatizada como uma clara identificação de um contexto de transferência privatizadora, já que é operada uma verdadeira deslocação no sentido do privado, não deixa de resultar subtraído de normas constituídas pelo direito público, sendo que a organização e atuação acabam por resultar temperadas pela emergência da necessidade de manter a atuação subordinada aos primados do direito público e à instituição da função jurisdicional que cabe exclusivamente ao Estado, apesar das chamadas de crise que têm vindo a ser invocadas ${ }^{3}$.

Partindo do pressuposto assumido de que a qualificação de certo fenómeno como uma privatização passará pela suscetibilidade do mesmo ser configurado como uma

\footnotetext{
${ }^{2}$ ESTORNINHO, M. J. A Fuga Para o Direito Privado, Contributo para o estudo da actividade de direito privado da Administração Pública. Coimbra: Almedina, 1996.

${ }^{3}$ SPENGLER, F. M. A crise do estado e a crise da jurisdição: (in)eficiência face à conflituosidade social. Revista Brasileira de Direito, IMED, v. 7, Jan-Jun 2011. ISSN 1.
} 
Revista Eletrônica de Direito Processual - REDP.

Rio de Janeiro. Ano 15. Volume 22. Número 2. Maio a Agosto de 2021

Periódico Quadrimestral da Pós-Graduação Stricto Sensu em Direito Processual da UERJ

Patrono: José Carlos Barbosa Moreira (in mem.). ISSN 1982-7636. pp. 540

www.redp.uerj.br

transferência de poderes ou de atuação para um domínio privado, fica aberto o caminho para uma panóplia de situações muito diversificadas. Podemos falar, assim, de supressão de poder regulador que os privados têm na sua atuação, face ao que teriam os agentes públicos; podemos referir que o setor privado cria um conjunto de normas que regulam as respetivas atividades; ou ainda uma transferência do objeto em que a atuação cabe aos privados, mas regulados pelas normas de direito público e supervisionados por órgãos públicos que mantêm a sua função de supervisão e de guardiões da legalidade.

Em todas elas acabamos por reconduzir ao axioma de que a substituição lógica é feita pela substituição do Estado pela sociedade, na qual a primeira recua na funcionalidade do interesse público, acompanhado de um avanço pela segunda naquele domínio. Este entendimento, apesar de correto, deve ser concebido com cuidado e com feições que interessam indicar, pois não falamos de uma despreocupação do Estado ou abandono deste no cumprimento do interesse público subjacente aos ideais de justiça, mas sim do aproveitamento do potencial privado para cumprimento deste desiderato, no qual estes acabam por ser instituídos na obrigação de assumir a transferência da responsabilidade e o ónus de cumprimento deste interesse. Caberá, assim, reconduzir à ideia que o interesse público acaba por ser potenciado por via da chamada do domínio privado ao cumprimento de atuações que até bem pouco cabiam à esfera pública, pelo que acabam por se outorgar nesta responsabilidade em medidas repartidas e partilhadas.

A potencialidade do domínio privado acaba assim por revelar a necessidade de transferir certos poderes públicos para a alçada destes, pois enquanto estes conseguem o aproveitamento de todo o potencial que têm ao seu dispor, quer a nível organizacional, económico, funcional e humano, o Estado acaba por se mostrar limitado em certos aspetos que a jusante restringem a sua atuação e consequentemente a concretização do interesse público e a lesão de direitos e interesses legalmente protegidos dos sujeitos. Por este motivo, quando opera uma privatização de determinado fenómeno acabamos por reformular a própria ideia e modelo de Estado vigente, encontrando-se assim associado a esta privatização do interesse público. A convocação da concretização do interesse público acaba por poder ser requerida à luz do primado do princípio da eficiência na prossecução da justiça. Basta, para o efeito, que se verifique uma atuação mais eficiente e se assuma como mais rentável funcional e financeiramente do que uma justiça não privatizada. 
Revista Eletrônica de Direito Processual - REDP.

Rio de Janeiro. Ano 15. Volume 22. Número 2. Maio a Agosto de 2021

Periódico Quadrimestral da Pós-Graduação Stricto Sensu em Direito Processual da UERJ

Patrono: José Carlos Barbosa Moreira (in mem.). ISSN 1982-7636. pp. 540

www.redp.uerj.br

Apesar de oriundos e desenvolvidos no seio da economia, os conceitos de eficiência e de eficácia acabam por se mostrar relevantes no contexto jurídico enquanto componentes de um princípio enformador da atuação do Estado na tarefa jurisdicional a que os tribunais estão incumbidos. Assumindo o conceito de eficiência um conceito polissémico, deve-se referir que num sentido amplo abrange o aproveitamento do potencial privado para, com aproveitamento dos meios e recurso que tem ao seu dispor e segundo critérios de razoabilidade e aproveitamento, conseguir a obtenção de resultados ótimos com o menor custo possível associado.

Importa assim considerar o primado de eficiência que acaba por estar compreendido do teor do n..$^{\circ}$ artigo 20. ${ }^{\circ}$ da Constituição da República Portuguesa, quando expressamente consagra que "todos têm direito a que uma causa em que intervenham seja objecto de decisão em prazo razoável e mediante processo equitativo" (sublinhado nosso). No mesmo sentido, o $\mathrm{n}^{\mathrm{o}} 1$ do artigo 6. ${ }^{\circ}$ da Convenção Europeia dos Direitos do Homem, abrange a obrigatoriedade de os Estados facultarem aos cidadãos, o acesso aos tribunais e à tutela jurisdicional efetiva dos direitos em tempo útil e segundo um processo equitativo. Enquanto dever que impende sobre os Estados, a obrigatoriedade de uma justiça célere e em tempo útil, obriga-os a procurar mecanismos e instrumentos que lhes permita satisfazer estes primados de eficiência e de razoabilidade temporal nas decisões emanadas pelos órgãos jurisdicionais competentes, pelo que o aproveitamento do potencial privado e dos recursos que estes dispõem numa tarefa que se possibilita juridicamente possível e aceitável de transferir, parcialmente, para os privados, concretiza este desiderato de eficiência na gestão da justiça e na obtenção de resoluções céleres.

Atento o exposto, não se pode deixar de afirmar que a privatização da ação executiva é movida por uma panóplia de fundamentos ontológicos que serviriam interesses de diversos domínios sociais, contudo o próprio conceito polissémico de privatização encerra em si um conjunto heterogéneo de entendimentos que dificilmente conseguem dar um entendimento uniforme, exaustivo e perentório a um fenómeno que se verifica denso e dificilmente encerrado na sociedade e nos ordenamentos jurídicos modernos. $\mathrm{O}$ chamamento do potencial privado e a sua fundamentação axiológica acaba por despertar interesses que até aqui não se tinham pensado, mas que devidamente comportam importantes benefícios que não podem ser negados nem, minimamente, negligenciados, 
Revista Eletrônica de Direito Processual - REDP.

Rio de Janeiro. Ano 15. Volume 22. Número 2. Maio a Agosto de 2021

Periódico Quadrimestral da Pós-Graduação Stricto Sensu em Direito Processual da UERJ

Patrono: José Carlos Barbosa Moreira (in mem.). ISSN 1982-7636. pp. 540

www.redp.uerj.br

sob pena de cairmos numa redundância que nos leve a enfermar e a ajuizar o entendimento enquanto meros artesãos de ideias.

\section{OPERACIONALIZAÇÃO DA PRIVATIZAÇÃO DA AÇÃO EXECUTIVA}

O processo executivo próprio do Direito processual português teve um progressivo desenvolvimento ao longo dos séculos, contudo a sua origem remonta à idade romana, como grande parte das instituições de direito vigentes nos vários ordenamentos jurídicos ${ }^{4}$. Contudo, não podemos deixar de referir que a sua expressividade sociológica se mostrou sempre como secundária ou subsidiária do processo de declaração judicial, mostrando-se como um tertium genus, cuja expressão sociológica se revela menos conhecida na vida social.

Todavia, no primeiro Código de Processo Civil português que remonta aos anos de 1876, já se encontrava no projeto de Alexandre Seabra, um conjunto de documentos que serviriam de título executivo para impulsionar o Estado na sua função jurisdicional de cumprimento coercivo das obrigações a que os sujeitos estavam adstritos. A par disto, previam-se ainda os documentos a favor da Fazenda Nacional como títulos bastantes para serem despoletadas as competentes ações de natureza executiva.

Tanto as posteriores reformas de 1939 e de 1961, mantiveram a sistematização da ação executiva, pois a tramitação do mesmo cabia na alçada dos tribunais enquanto guardiões do poder jurisdicional que cabe ao Estado. Contudo, não foi até a reforma de 2003 do Código de Processo Civil, considerando o Governo em funções, a ineficiência do tradicional processo executivo e movidos por uma necessidade de justiça célere e procurando dar cumprimento ao desiderato constitucional de que os sujeitos têm direito a obter em tempo útil a pretensão do seu direito, que se procurou uma alternativa ao paradigma tradicional, fazendo nele intervir profissionais liberais especializados, os solicitadores de execução, figura inspirada nos huissiers de justice franceses. A adoção deste modelo tinha vindo a ser alargada a países vizinhos de França, bem como a Estados do Leste Europeu, após o colapso dos respetivos regimes comunistas. Foi nesta lógica que se iniciou a desjudicialização do processo executivo, ou como também é designada, a sua

\footnotetext{
${ }^{4}$ RIBEIRO, A. O Processo Executivo no Futuro Código de Processo Civil, p. 87-147.
} 
Revista Eletrônica de Direito Processual - REDP.

Rio de Janeiro. Ano 15. Volume 22. Número 2. Maio a Agosto de 2021

Periódico Quadrimestral da Pós-Graduação Stricto Sensu em Direito Processual da UERJ

Patrono: José Carlos Barbosa Moreira (in mem.). ISSN 1982-7636. pp. 540

www.redp.uerj.br

privatização, pois a degradação do processo executivo no paradigma tradicional motivou a transferência de poderes públicos para a alçada destes privados.

Em termos de direito comparado, coexistem três modelos que operam no processo executivo, indo desde um extremo no qual o processo passou para uma lógica puramente administrativista, adotada em países escandinavos, outro que assenta num modelo de execução concentrado no tribunal judicial, configurando o outro extremo oposto, e um modelo misto ou hibrido que pretende uma parcial privatização no qual parte da atividade é realizada por agentes privados com a adoção de um órgão jurisdicional que procura a tutela dos atos praticados (modelo no qual assenta o direito português vigente e os casos do Huissier de justice em França ou ainda do Gerichtsvollzieher germânico ou do Bailiff anglo-americano $)^{56}$. Consegue-se verificar um espectro quantitativo que permite decifrar a maior ou menor medida com que a privatização do processo executivo é operada, sendo que a adoção por cada modelo assenta em primados constitucionais e no respeito pelos valores axiológicos vigentes. Dai que o sistema jurídico português não possa assentar a privatização da ação executiva num modelo extremista de privatização total, pois os valores axiológicos que obrigam a que a função jurisdicional do Estado seja exercida em exclusivo pelo Tribunal, não permitem uma ótica de privatização que assente na adoção de "desguarda" dos atuais agentes de execução, obrigando a coexistir órgãos jurisdicionais e não jurisdicionais no seio da ação executiva.

Foi com a aprovação da reforma de 2003 que se deu o primeiro passo para esta privatização do processo executivo, a qual foi aprovada pelo Decreto-Lei n. ${ }^{\circ} 38 / 2003$, de 8 de março, o qual viria a ser posteriormente alterado pelo Decreto-Lei n. ${ }^{\circ} 199 / 003$, de 10 de setembro, os quais tiveram uma profunda influência do Prof. Lebre de Freitas. O desiderato era claro e procurou que a atividade executiva dos tribunais, parcialmente, fosse realizada pelos solicitadores de execução, havendo, contudo, determinadas atividades e atuações que cabiam exclusivamente aos tribunais, bem com os poderes de supervisão do juiz era reforçado para garantia da tutela jurisdicional efetiva. Foi esta reforma que acabou por colocar um termo na concentração do processo executivo ancorado numa lógica de

\footnotetext{
${ }^{5}$ FREITAS, J. L. D. Agente de Execução e Poder Jurisdicional. Revista Themis, v. 7, VII.

${ }^{6}$ FREITAS, J. L. D. A Reforma do Processo Executivo. Revista da Ordem dos Advogados, Ano 62, v. II, 2002. ISSN 731-757.
} 
Revista Eletrônica de Direito Processual - REDP.

Rio de Janeiro. Ano 15. Volume 22. Número 2. Maio a Agosto de 2021

Periódico Quadrimestral da Pós-Graduação Stricto Sensu em Direito Processual da UERJ

Patrono: José Carlos Barbosa Moreira (in mem.). ISSN 1982-7636. pp. 540

www.redp.uerj.br

tramitação puramente concentrada no tribunal e nos funcionários judiciais orientados pelos juízes. Como refere TAVARES DE SOUSA:

"a reforma agora empreendida apresenta o mérito de procurar romper com o estado de coisas anterior, através de medidas destinadas a libertar os tribunais de atos que fracassavam por falta de meios logísticos adequados, atribuindo-se aos agentes de execução, em regra solicitadores especializados, uma parte das competências antes pertencentes a juízes e oficiais de justiça. A par desta «privatização» da competência para a prática de atos executivos, a intervenção legislativa recaiu sobre dois outros pontos onde se centravam os maiores entraves à funcionalidade do processo executivo: a dificuldade de conhecer com exatidão e em tempo útil a situação patrimonial do executado e, também, as demoras causadas pela citação edital dos credores com direitos reais de garantia não sujeitos a registo sobre os bens penhorados" $"$.

Não implicou, assim, uma atribuição de jurisdictio aos particulares, pois o Estado na sua função jurisdicional mantém o mister de prolação da tutela jurisdicional efetiva para a resolução de conflitos existentes, sendo atribuídas competências próprias às sujeições e prerrogativas judiciárias, na qual são transferidas por disposições legais expressas as mencionadas competências ${ }^{8}$.

A privatização acabou por ser dada pela redação dada ao artigo $808 .^{\circ}$ do Código de Processo Civil vigente, passando a prever o n. ${ }^{\circ} 1$ que "cabe ao agente de execução, salvo quando a lei determine diversamente, efetuar todas as diligências do processo de execução, incluindo citações, notificações e publicações, sob controlo do juiz", cabendo a este último o "poder geral do controlo do processo e de outras intervenções especificamente estabelecidas", tais como proferir despacho liminar, julgar incidentes de natureza declarativa, etc. (cf. artigo 809. ${ }^{\circ}$ do Código de Processo Civil de 1961). Como apontava alguma doutrina:

"uma consequência geral do novo regime definido para a ação executiva é a de que é admissível que uma execução corra totalmente sem que nela se chegue a verificar qualquer intervenção do juiz de execução (mas, naturalmente, sem que se dispense que o requerimento executivo deva ser entregue no Tribunal competente)"'.

\footnotetext{
${ }^{7}$ SOUSA, T. D. Código de Processo Civil. 8a . ed. Coimbra: Coimbra Editora, 2008.

${ }^{8}$ CALDAS, R. C. D. S. G. O modelo de desjudicialização colaborativa da execução civil Portuguesa: uma abordagem a partir dos seus procedimentos e sua aplicabibilidade ao Brasil. Revista de Direito Brasileira. Florianólopis, SC. v. 25, n. 10, p.345-365. Jan./Abr. 2020

${ }^{9}$ SOUSA, M. T. D. A Reforma da Ação Executiva. Lisboa: Lex Editora, 2004.
} 
Revista Eletrônica de Direito Processual - REDP.

Rio de Janeiro. Ano 15. Volume 22. Número 2. Maio a Agosto de 2021

Periódico Quadrimestral da Pós-Graduação Stricto Sensu em Direito Processual da UERJ

Patrono: José Carlos Barbosa Moreira (in mem.). ISSN 1982-7636. pp. 540

www.redp.uerj.br

A eficiência acabou assim por ser conseguida quer por via do chamamento do potencial privado ao cumprimento de tarefas que até então estavam exclusivamente na alçada do domínio público, designadamente dos tribunais comuns, bem como através de determinados mecanismos de celeridade e simplificação da tramitação do processo executivo.

Contudo, o bom funcionamento, ainda que com algumas críticas e prolixidades face à novidade oriundas da alteração de paradigma pois "o que é novo incomoda", acabou por determinar que a privatização fosse estendida em 2008, a qual foi apelidada pelo Prof. Lebre de Freitas de "Reforma da reforma da ação executiva"10, acabou por ser aprovada pelo Decreto-Lei n. ${ }^{\circ} 26 / 2008$, de 20 de novembro, o qual consagrava no seu preâmbulo que visava "tornas as execuções mais simples e eliminar formalidades processuais desnecessárias".

Da ótica da privatização operada com esta reforma, e deixando de lado aspetos processuais que procuraram uma simplificação do processo executivo e das formalidades inerentes e associadas ao mesmo, dir-se-á que esta acabou por culminar mais um passo na fase de privatização da ação executiva, pois se por um lado foram reforçados os poderes dos solicitadores de execução, que passaram a designar-se por agentes de execução - dada a possibilidade de também advogados com inscrição em vigor na respetiva ordem poderem exercer as funções no âmbito da ação executiva, contrariamente ao que ocorrera com a reforma de 2003 cuja delimitação estava circunscrita aos solicitadores -, também se verificou que o juiz passou a deter um poder de controlo sobre os atos praticados pelo agente de execução, unicamente quando fosse requerida a sua intervenção e dentro do elenco taxativo de poderes que a lei lhe conferia. Isto porque, o novo diploma veio expressamente eliminar, de forma emblemática, o "poder geral de controlo" que detinha desde a reforma de 2003, e consagrou que ao agente competia "lei determine o contrário, efetuar todas as diligências de execução, incluindo, nos termos da portaria do membro do Governo responsável pela área da justiça, as citações, notificações e publicações”. Prevê-se uma autêntica autonomização da figura do agente de execução e uma clara destrinça entre os intervenientes da ação executiva, deixando bem patente que a figura deste revelava ser o

${ }^{10}$ FREITAS, J. L. D. Os paradigmas da ação executiva. Estudos de Direito Civil e Processo Civil, Coimbra, 2002. 
Revista Eletrônica de Direito Processual - REDP.

Rio de Janeiro. Ano 15. Volume 22. Número 2. Maio a Agosto de 2021

Periódico Quadrimestral da Pós-Graduação Stricto Sensu em Direito Processual da UERJ

Patrono: José Carlos Barbosa Moreira (in mem.). ISSN 1982-7636. pp. 540

www.redp.uerj.br

"senhor da ação executiva", uma vez que cabia-lhe toda a tarefa inerente à tramitação do processo, funcionando mesmo como uma figura residual a quem lhe competia tudo o que não coubesse aos demais, deixando as funções do juiz de execução, da secretaria judicial e do oficial de justiça bem delimitadas e apenas em situações especificas e concretas.

O terceiro momento que se encontrou como concretizador do fenómeno de privatização do processo executivo, mostra-se com a aprovação do novo Código de Processo Civil de 2013, o qual foi aprovado pela Lei n. ${ }^{\circ} 41 / 2013$, de 26 de junho. Em termos sistematológicos, deve-se referir que a reforma do Código de Processo Civil de 2013 não trouxe alterações quanto aos poderes atribuídos ao agente de execução, nem quanto a este fenómeno de privatização, sendo pelo contrário verificada uma lógica de regressão desta privatização, uma vez que alguns dos poderes que haviam sido atribuídos ao agente de execução na reforma de 2008 retornaram à esfera do juiz de execução. Todavia, não se pode referir que tenham sido uma regressão profunda ou significativa que origine a ideia ou a máxima socialista que cause ou abale a figura da privatização da ação executiva e a sua subsequente devolução ao domínio exclusivamente público.

Por último, deve aqui ser apontado como instrumento legislativo que tornou operativo este processo translativo de poderes do domínio público para o domínio privado, a criação de um procedimento designado por Procedimento Extrajudicial Pré-Executivo (PEPEX), que procurou dar um passo mais neste fenómeno. O PEPEX, aprovado pela Lei n. ${ }^{3} 32 / 2014$, de 30 de maio, revela-se como um procedimento cuja natureza é facultativa e que corre termos de forma extrajudicialmente, ou seja, não tem qualquer movimentação ou inserção num processo de natureza jurisdicional. Axiologicamente, o elemento argumentativo que permite identificar este procedimento enquanto movimento privatizador do processo executivo é que o seu objeto é, precisamente, a fase 1 do processo de execução civil. Veja-se que o processo executivo para pagamento de quantia certa quando deva seguir forma sumária, nos termos e para efeitos do $\mathrm{n} .{ }^{\circ} 2$ do artigo $5500^{\circ}$ do Código de Processo Civil de 2013, acaba por encerrar na sua fase 1 as diligências de análise do título e requerimento executivo, bem como as diligências prévias à penhora, na qual o Agente de Execução irá averiguar a existência de bens que sejam suscetíveis de penhora e notificar o exequente do teor da fase 1 para que este se venha a pronunciar no prazo de 5 dias sobre o andamento do processo, ou a sua eventual desistência. Compulsada a Lei n. ${ }^{\circ} 32 / 2014$, de 30 
Revista Eletrônica de Direito Processual - REDP.

Rio de Janeiro. Ano 15. Volume 22. Número 2. Maio a Agosto de 2021

Periódico Quadrimestral da Pós-Graduação Stricto Sensu em Direito Processual da UERJ

Patrono: José Carlos Barbosa Moreira (in mem.). ISSN 1982-7636. pp. 540

www.redp.uerj.br

de maio, a qual aprovou o PEPEX, verifica-se que a sistematologia deste procedimento é precisamente retirar a fase 1 do processo executivo para a alçada dos privados, procurando transferir esta fase para um procedimento puramente administrativo que visa, entre outras, analisar o título e requerimento executivos e encontrar bens suscetíveis de penhora.

Conforme referido, denota-se do teor do artigo $2 .^{\circ}$ da Lei n. ${ }^{\circ} 32 / 2014$, de 30 de maio, que o PEPEX tem como desiderato, entre outras, a:

"identificação de bens penhoráveis através da disponibilização de informação e consulta às bases de dados de acesso direto eletrónico previstas no Código de Processo Civil , aprovado pela Lei n. ${ }^{\circ}$ 41/2013, de 26 de junho, para os processos de execução cuja disponibilização ou consulta não dependa de prévio despacho judicial”.

Acresce o n. ${ }^{\circ} 1$ do artigo $9 .^{\circ}$ do citado diploma legal que:

"o agente de execução realiza as consultas às bases de dados da administração tributária, da segurança social, do registo civil, do registo nacional de pessoas coletivas, do registo predial, do registo comercial e do registo de veículos e de outros registos ou arquivos semelhantes, para obtenção de informação referente à identificação e localização do requerido, bem como dos bens penhoráveis de que seja titular".

Analogamente, determina, já em sede de processo de execução, o n. ${ }^{\circ} 1$ do artigo 749. ${ }^{\circ}$ do Código de Processo Civil de 2013, que:

"a realização da penhora é precedida das diligências que o agente de execução considere úteis à identificação ou localização de bens penhoráveis, observado o disposto no $n .^{\circ} 2$ do artigo $751 .^{\circ}$, a realizar no prazo máximo de 20 dias, procedendo este, sempre que necessário, à consulta, nas bases de dados da administração tributária, da segurança social, das conservatórias do registo predial, comercial e automóvel e de outros registos ou arquivos semelhantes, de todas as informações sobre a identificação do executado junto desses serviços e sobre a identificação e a localização dos seus bens".

Como se pode verificar desta comparativa legislativa, torna-se claro e indubitável que o desiderato prosseguido pelo legislador foi privatizar parcialmente o processo executivo de pagamento de quantia certa, sempre que esta corra sob a forma sumária, retirando da alçada da natureza jurisdicional a fase 1 do processo executivo para uma total privatização, uma vez que tanto as normas como o seu funcionamento são determinados por normas jurídicas que se caraterizam pela sua natureza extrajudicial e procedimental. Revela-se, assim, que este foi a última, e decisiva, vontade movida pelo legislador com o intuito de concretizar a privatização do processo executivo, de modo a transferir poderes 
Revista Eletrônica de Direito Processual - REDP.

Rio de Janeiro. Ano 15. Volume 22. Número 2. Maio a Agosto de 2021

Periódico Quadrimestral da Pós-Graduação Stricto Sensu em Direito Processual da UERJ

Patrono: José Carlos Barbosa Moreira (in mem.). ISSN 1982-7636. pp. 540

www.redp.uerj.br

que se encontravam na alçada do domínio público para o domínio privado, sendo nesta fase realizada uma privatização que deve ser considerada verdadeiramente como pura e movida pela alteração substancial das normas jurídicas que lhe dão regulamentação.

\section{OS LIMITES DA PRIVATIZAÇÃO DA AÇÃO EXECUTIVA}

O fenómeno de privatização da ação executiva enquanto alteração do paradigma clássico baseado na exclusividade do poder público encerrado na esfera jurisdicional dos tribunais para uma ótica de aproveitamento do potencial privado, dando-lhes competências que até há bem pouco tempo competiam aos tribunais judiciais, acaba por comportar uma importante alteração do funcionamento da justiça e na própria exteriorização social da mesma, enquanto garante de um Estado de Direito baseado em sistemas públicos hierarquizados, equitativos e justos na resolução de litígios.

Por isso, estudado o fenómeno da privatização e as suas concretizações, impõe-se, neste momento, dirigir a nossa atenção para os limites a este fenómeno e como os mesmos se podem impor. Decerto será, e sem prejuízo dos limites que se possam levantar a outros níveis, que os limites poderão ser de diversa índole, designadamente limites práticos, sociológicos, éticos ou mesmo políticos, contudo a nossa atenção mostrar-se-á exclusivamente dirigida para os limites de natureza jurídica que podem levantar-se com esta privatização.

Primo, podemos apontar como primeiro limite na privatização da ação executiva, o princípio da eficiência já mencionado ao longo deste breve trabalho, pois este acaba por comportar e representar um duplo papel relativamente a este fenómeno de privatização da ação executiva. Enquanto se assume como um elemento motivador da privatização, não podemos negligenciar que também se carateriza como um limite da mesma. Em termos concetuais, não podemos olvidar que o conceito de eficiência é um conceito relativo, concretizando uma ponderação entre o nível de resultados obtidos com a ação executiva e o nível de recursos afetos à sua obtenção; por outro lado, não podemos deixar de considerar que o nível de resultados obtidos, determina a necessidade de serem cumpridas determinadas finalidades. Quer isto dizer que, quando a privatização opere para um nível 
Revista Eletrônica de Direito Processual - REDP.

Rio de Janeiro. Ano 15. Volume 22. Número 2. Maio a Agosto de 2021

Periódico Quadrimestral da Pós-Graduação Stricto Sensu em Direito Processual da UERJ

Patrono: José Carlos Barbosa Moreira (in mem.). ISSN 1982-7636. pp. 540

www.redp.uerj.br

de ineficácia ou ineficiência, a privatização deixará de ser uma solução para ser considerada uma problemática.

Pelo exposto, torna-se possível identificar uma harmonia entre a necessidade de reduzir custos associados à gestão do processo executivo e a necessidade de obtenção de resultados concretos da ação executiva e da concretização do interesse público. $\mathrm{O}$ específico interesse público subjacente à realização das finalidades da ação executiva não poderá ser prejudicado pelo fenómeno da privatização, e nessa medida constituirá o seu limite enquanto elemento intransponível deste fenómeno.

Secundo, o regime constitucional das restrições de direitos, liberdades e garantias configura-se aqui como um importante limite perante a privatização da ação executiva, contendendo a necessidade acrescida de salvaguarda dos direitos, liberdades e garantias fundamentais dos sujeitos que passaram a ser destinatários de uma multiplicidade de atos praticados por agentes privados investidos por poderes públicos. As normas por via das quais se concretizam as medidas restritivas de apreensão de bens pertencentes ao património do devedor e executado, dificilmente se poderão deixar de ser tidas como restritivas, porque, apesar de no interesse público e não do Agente de Execução, não são acompanhadas de um interesse ou remuneração por parte deste.

O primeiro aspeto a ter em consideração e que se deve aqui salientar, contende com o facto de a privatização transferir poderes públicos restritivos de direitos para a alçada do domínio dos privados, ficando estes investidos de verdadeiros poderes coercivos que lhes permite limitar a atuação dos direitos que os executados detêm sobre os seus bens. Ora, consubstanciando-se em atos privativos de direitos, liberdades e garantias há que ter um certo cuidado na translação destes poderes para a alçada dos privados, bem como a forma como a mesma é concretizada, pois outorgar poderes limitativos de direitos constitucionalmente consagrados unicamente poderá ser realizada tendo em consideração os primados de necessidade, adequação e proporcionalidade ${ }^{11}$.

Um segundo aspeto que não deve aqui ser negligenciado contende com a liberdade de escolha de profissão vertida no artigo 47. ${ }^{\circ}$ da Constituição da República Portuguesa e gizada em muitas das Constituições modernas. Veja-se que um dos anteprojetos do

\footnotetext{
11 GOMES CANOTILHO, J. J.; MOREIRA, V. Constituição da República Portuguesa. 4ª. ed. Coimbra:
} Coimbra Editora, v. I, 2007. 
Revista Eletrônica de Direito Processual - REDP.

Rio de Janeiro. Ano 15. Volume 22. Número 2. Maio a Agosto de 2021

Periódico Quadrimestral da Pós-Graduação Stricto Sensu em Direito Processual da UERJ

Patrono: José Carlos Barbosa Moreira (in mem.). ISSN 1982-7636. pp. 540

www.redp.uerj.br

Estatuto da Ordem dos Solicitadores e Agentes de Execução, limitava mesmo o exercício da profissão de solicitador ou advogado para aqueles que desejassem inscrever-se enquanto agentes de execução, não podendo exercer qualquer outra atividade que não esta última mencionada. Tal limitação acabou por não ser aprovada no texto final do Estatuto aprovado, contudo a limitação que a privatização da ação executiva impõe a certos direitos, liberdades e garantias pode mostrar uma importante atividade limitativa a estes.

Tertio, deve-se apontar como um dos limites impostos para que a privatização da ação executiva não ocorra de forma totalmente administrativista, o exercício da função jurisdicional por parte do Estado em função de monopólio. Veja-se que o artigo $202 .^{\circ}$ da Constituição da República Portuguesa, consagra expressamente que "os tribunais são os órgãos de soberania com competência para administrar a justiça em nome do povo", sendo que "na administração da justiça incumbe aos tribunais assegurar a defesa dos direitos e interesses legalmente protegidos dos cidadãos, reprimir a violação da legalidade democrática e dirimir os conflitos de interesses públicos e privados”. Ou seja, segundo alguns autores, a ausência de enquadramento sistemático dos tribunais de outra natureza ou da possibilidade de que a justiça seja administrativa por entes privados, leva à velha máxima de que o Estado possui o monopólio da jurisdictio.

Contudo, não podemos dizer que estejamos perante uma verdadeira privatização em sentido estrito, pois como temos vindo a referir a privatização operada deve ser entendida unicamente num sentido amplo, pois parte dos poderes mantêm-se na esfera jurídica do tribunal, sendo o juiz o guardião da lei e da função jurisdicional em matéria executiva. Como refere LEBRE DE FREITAS:

"além do controlo prévio da execução [...] cabe ao juiz julgar a reclamação de qualquer acto do agente de execução e decidir qualquer questão que lhe seja suscitada por este, pelas partes [...] por terceiros intervenientes [...] ou em certos casos por funcioná- rio judicial [...] Por via destas atribuições [...] é assegurado o controlo à posteriori dos actos executivos, sobre os quais cabe sempre ao juiz a última palavra. Mas além de oficiosamente poder dar-se conta, em momento em que o processo the seja concluso, de qualquer questão que não the tenha sido suscitada, conservando sempre o poder de controlo geral do processo, várias disposições legais apelam para a sua intervenção"12.

\footnotetext{
${ }^{12}$ FREITAS, J. L. D. Agente de Execução e Poder Jurisdicional. Revista Themis, v. 7, VII.
} 
Revista Eletrônica de Direito Processual - REDP.

Rio de Janeiro. Ano 15. Volume 22. Número 2. Maio a Agosto de 2021

Periódico Quadrimestral da Pós-Graduação Stricto Sensu em Direito Processual da UERJ

Patrono: José Carlos Barbosa Moreira (in mem.). ISSN 1982-7636. pp. 540

www.redp.uerj.br

Denota-se, assim, que a transferência de poderes operada por via desta privatização, acaba por se mostrar limitada por este princípio constitucional que veda a terceiros ou a privados, a prática de atos de natureza jurisdicional, devendo os mesmos agir em representação do tribunal. Por este motivo, MARCO CONÇALVES acaba por expressamente referir que ao agente de execução compete, fundamentalmente, a tarefa de auxiliar a justiça com um poder geral de direção do processo $^{13}$. A função do Agente de execução é assim a mera tarefa de auxílio e da prática de tarefas de expediente ou executivas que podiam ser praticadas pelos oficiais de justiça e não requerem a interpretação ou aplicação do direito em casos de litígio, não operando, assim, uma transmissão da função jurisdicional do Estado na sua vertente de resolução dos litígios que venham a ascender na ação executiva, pois nestes casos cabe ao juiz dirimir estes litígios.

Atento o exposto, a obrigatoriedade de que a função jurisdicional seja realizada unicamente pelos tribunais, acaba por marcar negativamente a pretensão de privatização pretendida pelo legislador, pois constitui esta uma verdadeira limitação efetiva no sentido de não poder ser concretizada uma total transferência de poderes para a alçada do domínio privado, uma vez que os limites constitucionais pautam que o modelo a adotar não possa meramente desprender-se da função jurisdicional exercida pelos tribunais e da função que estes encerram enquanto guardiões da resolução de litígios.

\section{CONCLUSÃO}

Terminamos enfatizando algo que viajou abscondido em cada uma das reflexões apontadas: não se é destituído de soluções mágicas que habilitem o autor a oferecer a solução definitiva para um fenómeno que se prolonga, há já vários anos, e que perdurará futuramente. Pretende-se, unicamente, dar um humilde contributo a uma problemática que, apesar de sui generis, se avoca como relevante e de difícil implementação no ordenamento jurídico dada as especificidades e vicissitudes que cada um dos contrapontos apresenta. Arrogar-nos de certezas num terreno que se considera "pantanoso" e desnivelado é, no mínimo, assumir soberbia e arrogância.

\footnotetext{
${ }^{13}$ GONÇALVES, M. Lições de Processo Civil Executivo. 2ª . ed. Coimbra: Almedina, 2018.
} 
Revista Eletrônica de Direito Processual - REDP.

Rio de Janeiro. Ano 15. Volume 22. Número 2. Maio a Agosto de 2021

Periódico Quadrimestral da Pós-Graduação Stricto Sensu em Direito Processual da UERJ

Patrono: José Carlos Barbosa Moreira (in mem.). ISSN 1982-7636. pp. 540

www.redp.uerj.br

Contudo, podemos afirmar algumas premissas que interessam concluir: a primeira, é a de que a privatização, enquanto fenómeno polissémico, não deixa de comportar importantes especificidades que devem ser casuisticamente ponderadas e analisadas quanto aplicadas em matérias relacionadas com o interesse público. Deste modo, não se poderão encontrar fórmulas matemáticas nem ciências exatas para encontrar respostas a esta problemática, devendo averiguar-se caso a caso para encontrar uma melhor solução ao problema colocado.

Uma segunda premissa a concluir insurge-se na forma de concretização com a qual se procurou operar esta privatização da ação executiva. Se bem entendidas as motivações, esta concretização acabou por ser realizada tendo por consideração os limites jurídicos que se apresentam como intransponíveis e que não poderão de se revelar como verdadeiras barreiras que impedem uma total transferência de poderes públicos, para o domínio dos entes privados.

Defendemos, assim, que ainda se apresente como benéfico e eficiente para a gestão da justiça e a concretização de ideais de eficiência, não se pode deixar de descuidar importantes limites que impedem a total transferência de poderes, devendo a ação executiva mover-se pelos meandros e da ação publicista e privatista. Não podemos, assim, viver acorrentados a ideais platónicos, dogmatizando um mundo ideal e ignorando o latejar da realidade e das problemáticas associadas, procurando, assim, dotar o intérprete de algumas soluções que mui humildemente nos parecem adequar os interesses de todos os intervenientes.

\section{REFERÊNCIAS}

CALDAS, R. C. D. S. G. O modelo de desjudicialização colaborativa da execução civil Portuguesa: uma abordagem a partir dos seus procedimentos e sua aplicabibilidade ao Brasil. Revista de Direito Brasileira. Florianólopis, SC. v. 25, n. 10, p.345-365. Jan./Abr. 2020.

ESTORninho, M. J. A Fuga Para o Direito Privado, Contributo para o estudo da actividade de direito privado da Administração Pública. Coimbra: Almedina, 1996. 
Revista Eletrônica de Direito Processual - REDP.

Rio de Janeiro. Ano 15. Volume 22. Número 2. Maio a Agosto de 2021

Periódico Quadrimestral da Pós-Graduação Stricto Sensu em Direito Processual da UERJ

Patrono: José Carlos Barbosa Moreira (in mem.). ISSN 1982-7636. pp. 540

www.redp.uerj.br

FREITAS, J. L. D. Os paradigmas da ação executiva. Estudos de Direito Civil e Processo Civil, Coimbra, 2002.

FREITAS, J. L. D. Agente de Execução e Poder Jurisdicional. Revista Themis, v. 7, VII.

FREITAS, J. L. D. A Reforma do Processo Executivo. Revista da Ordem dos Advogados, Ano 62, v. II, 2002. ISSN 731-757.

GOMES CANOTILHO, J. J.; MOREIRA, V. Constituição da República Portuguesa. 4a . ed. Coimbra: Coimbra Editora, v. I, 2007.

GONÇALVES, M. Lições de Processo Civil Executivo. 2a ${ }^{\text {a }}$ ed. Coimbra: Almedina, 2018.

RIBEIRO, A. O Processo Executivo no Futuro Código de Processo Civil, p. 87-147.

SOUSA, M. T. D. A Reforma da Ação Executiva. Lisboa: Lex Editora, 2004.

SOUSA, T. D. Código de Processo Civil. 8 . ed. Coimbra: Coimbra Editora, 2008.

SPENGLER, F. M. A crise do estado e a crise da jurisdição: (in)eficiência face à conflituosidade social. Revista Brasileira de Direito, IMED, v. 7, Jan-Jun 2011. ISSN 1. 